\title{
Near Vision Improvement with the Use of a New Topical Compound for Presbyopia Correction: A Prospective, Consecutive Interventional Non- Comparative Clinical Study
}

Veronica Vargas · Felipe Vejarano · Jorge L. Alió

Received: August 6, 2018 / Published online: November 21, 2018

(C) The Author(s) 2018

\section{ABSTRACT}

Introduction: To report the outcomes in near vision, optical quality and pupil diameter of a new pharmacological therapy (FOV tears) for presbyopia.

Methods: This was a prospective, consecutive, interventional, non-comparative clinical study in which 117 presbyopic patients were given one drop of the novel therapy (FOV tears) in each eye, followed $2 \mathrm{~h}$ after the instillation of the eye drop by an evaluation of the binocular uncorrected near visual acuity (UNVA) and uncorrected distance visual acuity. The objective scatter index and pupil diameter under photopic and scotopic conditions before and after instillation were also assessed. The patients were divided into two groups according to their age, with group 1 patients being 41 and 50 years

Enhanced Digital Features To view enhanced digital features for this article go to https://doi.org/10.6084/ m9.figshare.7309124.

V. Vargas · J. L. Alió $(\bowtie)$

Vissum Instituto Oftalmologico de Alicante, Alicante, Spain

e-mail: jlalio@vissum.com

F. Vejarano

Fundacion Oftalmologica Vejarano, Popayan, Colombia

J. L. Alió

Division of Ophthalmology, Universidad Miguel

Hernández, Alicante, Spain old and group 2 patients, between 51 and 65 years old.

Results: The mean age of the patients was 50.2 years. The mean UNVA before the use of the eye drop was 0.35 LogMAR, which improved to $0.16 \operatorname{LogMAR}$ at $2 \mathrm{~h}$ after the use of the eye drop $(p=0.000)$. Nine patients did not show an improvement in UNVA, but no patient showed a loss of lines. Fourteen patients $(11.9 \%)$ reported headaches as a side effect of the therapy.

Conclusion: This pharmacological therapy improved near vision by one or more lines (mean improvement 0.18 lines) in $92.3 \%$ of the patients at $2 \mathrm{~h}$ following the instillation of the eye drops. The group with the youngest patients gained more lines than the group with the oldest patients.

Keywords: Accommodation; Depth of focus; Near vision; Objective scatter index; Pharmacological treatment; Presbyopia; Pupil size; Refractive surgery

\section{INTRODUCTION}

Presbyopia is an age-related condition characterized by the progressive loss of accommodation clinically affecting the near vision performance. Most importantly, it affects the quality of life as it creates a dependence on glasses to perform near vision activities [1]. 
Most of the treatments available nowadays to restore spectacle independence for near vision activities are surgical and, hence, invasive either at the level of the cornea, lens, or sclera [2]. Multifocal intraocular lenses have demonstrated good visual outcomes but require lens or cataract surgery and are implanted in patients aged 50 or 55 years or older when the accommodation is lost completely. The least invasive surgical treatment of presbyopia is at the cornea; laser treatment with monovision or presbyLASIK and some intracorneal implants have demonstrated good outcomes, although there may be a loss of distance vision [3].

A non-invasive treatment, such as a topical one, that would avoid any type of surgery is an attractive option for both patients and doctors. We have proposed a novel pharmacological treatment of presbyopia, the FOV drops, which consists in the use of eye drops that contain a parasympathetic, a nonsteroidal anti-inflammatory drug, two alpha-agonists, and an anticholinesterase agent to restore near vision. A previous pilot study conducted by our group [4] confirmed the positive effect of this pharmacological combination on near vision performance.

The aim of this study was to further evaluate the improvement in near vision in patients receiving this pharmacological therapy (FOV tears) in a large-scale clinical study, which also included an investigation of the impact of this therapy on pupil size and on the Objective Scatter Index (OSI). The OSI is based on the principle of "double-pass" aberrometry and is a measure of forward-scattered light [5]; its level has been related with degradation of the quality of the image on the retina $[6,7]$.

\section{METHODS}

This was a consecutive, non-randomized, interventional, non-comparative clinical study in which 117 consecutive presbyopic patients participated. The mean age of the patients was $50.25 \pm 5.1$ (range 41-65) years. All patients aged between 41 and 65 years who were spectacle dependent for near vision and spectacle independent for far vision (i.e., patients could not perform near vision activities without the need of near addition), with binocular 0.0 logMAR in far vision, a refractive error of between 1.50 diopters (D) of hyperopia and $0.50 \mathrm{D}$ of myopia, and astigmatism of $<1.50 \mathrm{D}$ were included in the study. Exclusion criteria included previous refractive surgery, pseudophakia, significant comorbidities (including clinically relevant dry eye, glaucoma, or any type of retinal problem with a potential to influence the results of this study, and any known sensitivity to the components of the FOV tears preparation. The patients were divided by age into two groups (group 1: 41-50 years; group 2: 51-65 years) for the purpose of analyzing the outcomes and determining the eventual relationship of outcome with age.

Each patient received one eye drop of the FOV tears in each eye. The composition of FOV tears is pilocarpine $(0.247 \%)$, phenylephrine $(0.78 \%)$, polyethyleneglycol $(0.09 \%)$, nepafenac $(0.023 \%)$, pheniramine $(0.034 \%)$, and naphazoline $(0.003 \%)$.

Both visual acuities were evaluated before and $2 \mathrm{~h}$ after the instillation of the eye drop by a certified observer. Distance vision was measured with the ETDRS charts. Near vision was measured at a $40-\mathrm{cm}$ distance with the Rosenbaum chart with Jaeger notation which was then converted to LogMAR. To maintain the correct reading distance, the chart had a $40-\mathrm{cm}$-long cord attached. Immediately after the measurement of near vision, a double-pass instrument (OQAS; Visiometrics SL, Cerdanyola del Vallès, Spain) was used to quantify the magnitude of intraocular scattering, and pupil diameter was measured using an AL-Scan optical biometer (Nidek Co., Ltd., Gamagori, Aichi, Japan), both before and $2 \mathrm{~h}$ after the instillation of the eye drop into each eye.

The main outcomes were the binocular uncorrected near visual acuity (UNVA) and uncorrected distance visual acuity (UDVA). The secondary outcomes were the pupil diameter and the OSI.

The ethics committee of Fundación Oftalmológica Vejarano in Popayán, Colombia, approved the study, and each participant provided written informed consent. The study followed the Declaration of Helsinki of 1964, as 
revised in 2013 (Fortaleza, Brazil). The trial was not registered due to the short follow-up time (2 h).

\section{Statistical Analysis}

The statistical analysis was performed using SPSS software for Windows (version 15.0.1; IBM Corp., Armonk, NY, USA). Average values and standard deviations were calculated for every parameter during the follow-up. Normality of all data samples was evaluated by means of the Kolmogorov-Smirnov test. When parametric analysis was possible, the Student $t$ test for paired data was performed for all comparisons of parameters between the pre-eye drop instillation condition and the post-eye drop instillation condition. When parametric analysis was not possible, the Wilcoxon rank sum test was applied to assess the significance of differences between the pre-eye drop and post-eye drop data. For all statistical analyses, a $p$ value of $<$ 0.05 was considered to indicate statistical significance. Outliers were not included in the statistical analyses.

\section{RESULTS}

There was a statistically significant improvement in near vision $2 \mathrm{~h}$ after instillation of the eye drops $(p=0.000)$ in both groups (Table 1$)$. The difference in UNVA between the two groups was statistically significant both before the use of the eye drop ( $p=0.037)$ and $2 \mathrm{~h}$ after instillation of the eye drops $(p=0.022)$. Of the
117 patients, seven were myopes and the others were hyperopes.

The mean gain of lines in near vision was 1.8 lines (range 1-5 lines) (Figs. 1, 2). Nine patients

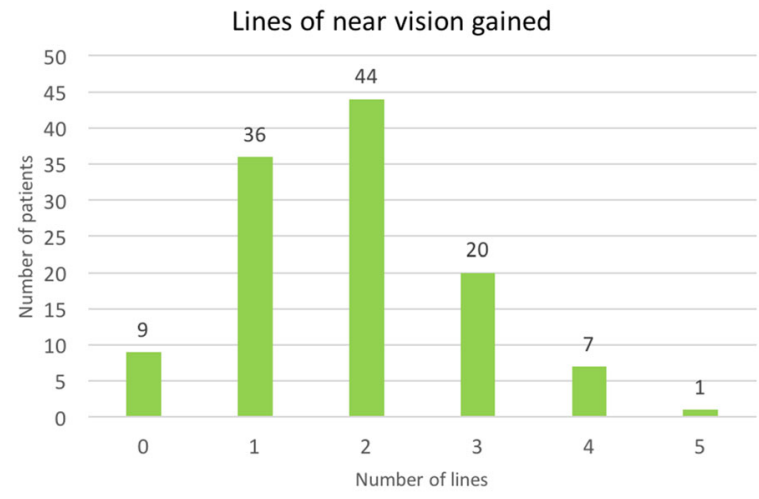

Fig. 1 Number of lines gained in near vision $2 \mathrm{~h}$ after instillation of one eye drop to each eye in all patients

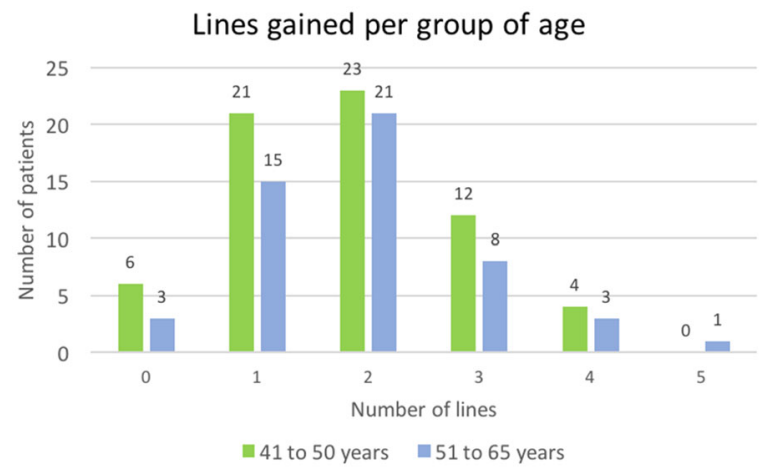

Fig. 2 Number of lines gained in near vision $2 \mathrm{~h}$ after instillation of one eye drop to each eye according to age group

Table 1 Patients data and uncorrected near visual acuity before and after instillation of the eye drop

\begin{tabular}{|c|c|c|c|c|c|c|c|c|c|c|}
\hline \multirow[t]{2}{*}{ Study groups } & \multirow[t]{2}{*}{ Number of patients } & \multicolumn{2}{|c|}{$\operatorname{Sex}(n)$} & \multicolumn{2}{|l|}{$\begin{array}{l}\text { Age } \\
\text { (years) }\end{array}$} & \multicolumn{2}{|c|}{$\begin{array}{l}\text { UNVA } \\
\text { before } \\
\text { instillation } \\
\text { (LogMAR) }\end{array}$} & \multicolumn{2}{|c|}{$\begin{array}{l}\text { UNVA } 2 \\
\text { after } \\
\text { instillation } \\
\text { (LogMAR) }\end{array}$} & \multirow[t]{2}{*}{$p$ value } \\
\hline & & Male & Female & Mean & $\overline{S D}$ & Mean & SD & Mean & SD & \\
\hline All patients & 117 & 73 & 44 & 50.2 & 5.1 & 0.35 & 0.15 & 0.16 & 0.11 & 0.000 \\
\hline Group 1 (age $41-50$ years) & 66 & 42 & 24 & 46.6 & 2.6 & 0.31 & 0.16 & 0.14 & 0.10 & 0.000 \\
\hline Group 2 (age $50-65$ years) & 51 & 31 & 20 & 55.0 & 3.2 & 0.38 & 0.14 & 0.19 & 0.12 & 0.000 \\
\hline
\end{tabular}

$S D$ Standard deviation, $U N V A$ uncorrected near visual acuity 
did not show any improvement in UNVA, but no patient lost lines of near vision. Of all eyes, the minimum near vision in the study before instillation of the eye drop was $0.7 \log M A R ; 2 \mathrm{~h}$ after instillation, the minimum near vision reported was $0.50 \log$ MAR.

The UDVA remained the same in all patients after instillation of the eye drop, with the exception of one patient who had an UDVA of $0.0 \log$ MAR prior to instillation and an UDVA of $0.2 \log$ MAR $2 \mathrm{~h}$ after instillation. There was a slight myopic shift of 0.25 to $0.50 \mathrm{D}$ after the use of the eye drop, but this shift was not statistically significant; there was also no statistically significant difference in the cylinder after the use of the eye drop (see Tables 2, 3 and 4).

Evaluation of light scattering with the double pass technique revealed that there was no significant change in the OSI before and after eye drop instillation ( $p=0.772)$ (Fig. 3 and Table 5). However, comparison of group 1 and group 2 eyes after the instillation of the eye drop did reveal a significant difference ( $p$ value of 0.001 for the right eye and $p: 0.012$ for the left eye).

In all 117 patients the mean pupil size decreased significantly under photopic conditions $(p=0.001)$, from $3.3 \mathrm{~mm}$ before treatment to $3.05 \mathrm{~mm}$ at $2 \mathrm{~h}$ after treatment (Fig. 4). The mean pupil size also decrease significantly under scotopic conditions $(p=0.000)$, from $4.9 \mathrm{~mm}$ before treatment to $3.9 \mathrm{~mm}$ at 2 after treatment (Fig. 5). This change was statistically significant in both group 1 and group 2 patients under both light conditions $(p=0.000)$ (Table 6). The change in pupil size between photopic and scotopic conditions was not significant in ( $p=0.591$ and 0.389 , respectively).

Fourteen patients reported headaches after instillation of the eye drop and one was intolerant to the eye drop.

\section{DISCUSSION}

The results of the present study with 117 patients show that the UNVA improved in almost all of the patients at $2 \mathrm{~h}$ post-eye drop instillation, with only nine patients having the same UNVA post-eye drop instillation as pre-eye drop instillation. As such, these results confirm

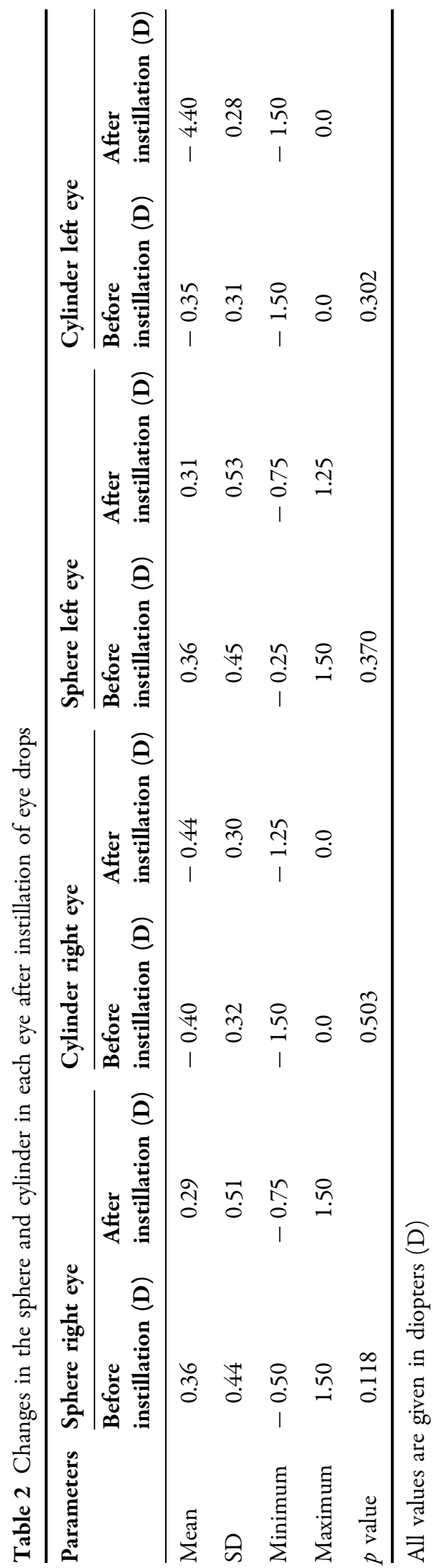


Table 3 Sphere and cylinder outcomes according to age group

\begin{tabular}{|c|c|c|c|c|c|c|}
\hline \multirow[t]{2}{*}{ Sphere/cylinder } & \multicolumn{3}{|l|}{ Right eye } & \multicolumn{3}{|l|}{ Left eye } \\
\hline & $\begin{array}{l}\text { Before instillation } \\
\text { (D) }\end{array}$ & $\begin{array}{l}\text { After instillation } \\
\text { (D) }\end{array}$ & $p$ value & $\begin{array}{l}\text { Before instillation } \\
\text { (D) }\end{array}$ & $\begin{array}{l}\text { After instillation } \\
\text { (D) }\end{array}$ & $p$ value \\
\hline Sphere group 1 & $0.31 \pm 0.46$ & $0.22 \pm 0.53$ & 0.225 & $0.32 \pm 0.45$ & $0.26 \pm 0.54$ & 0.650 \\
\hline Sphere group 2 & $0.35 \pm 0.47$ & $0.31 \pm 0.50$ & 0.131 & $0.31 \pm 0.43$ & $0.24 \pm 0.49$ & 0.365 \\
\hline Cylinder group 1 & $-0.32 \pm 0.22$ & $-0.35 \pm 0.30$ & 0.167 & $-0.35 \pm 0.35$ & $-0.42 \pm 0.33$ & 0.238 \\
\hline Cylinder group 2 & $-0.57 \pm 0.40$ & $-0.54 \pm 0.33$ & 0.380 & $-0.37 \pm 0.23$ & $-0.38 \pm 0.19$ & 0.797 \\
\hline
\end{tabular}

Values in table are presented as the mean $\pm S D$

Table 4 Comparison of the sphere and cylinder in both groups after instillation of eye drops

\begin{tabular}{lll}
\hline Sphere/cylinder & Right eye $\boldsymbol{p}$ value & Left eye $\boldsymbol{p}$ value \\
\hline Sphere & 0.668 & 0.860 \\
Cylinder & 0.207 & 0.877 \\
\hline
\end{tabular}

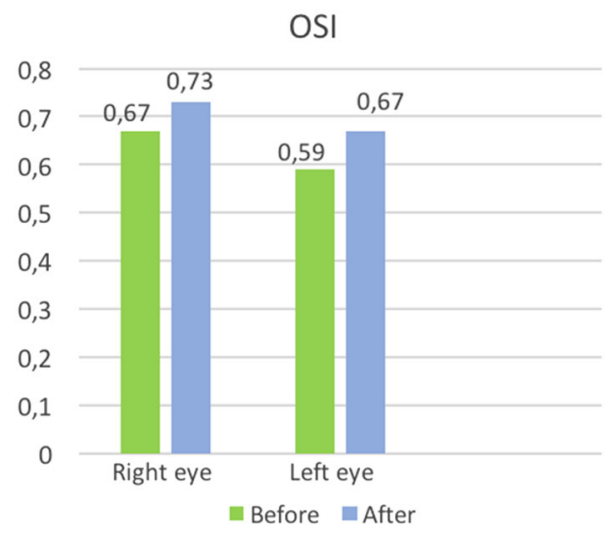

Fig. 3 Objective Scatter Index (OSI) results for the right and left eye before and after the instillation of the eye drop. There was no statistically significant change in values

the findings of our previous investigation [4], showing on a larger scale highly statistically significant differences in near vision and pupil diameter after the use of the eye drop preparation. Presbyopia is an age-related condition, and we therefore divided the patients into two age groups (group 1: 41-50 years; group 2:51-65 years); as it was expected, group 1 patients showed a greater improvement in near vision than did group 2 patients, although both groups showed a statistically significant improvement in near vision after the use of the eye drop. One possible explanation for this difference between groups may be that the younger patients have a greater residual function of accommodation than the older ones, so that after the use of the eye drop it was easier for them (group 1) to gain lines in near vision than the patients in group 2. Distance vision was not affected by use of the eye drop, with only a slightly myopic shift that was not statistically significant in either group. Pupil size changed significantly in both groups after the use of the eye drops, with no significant difference between groups. Due to the significant change in pupil size before and after the instillation of the eye drop, the mechanism of action would seem to be at least partially related to an increase in the depth of focus of the eye. Some accommodation may have been induced because when we compared patient groups, group 1 patients had better near visual outcomes than group 2 patients. Taking into account that pupil constriction was the same in both groups, we can speculate that this improvement in near vision in group 1 may be explained by a residual function of accommodation, although this has to be confirmed with an objective measurement.

We did not find any changes in the OSI after the instillation of the eye drops in all 117 patients, although when we compared group 1 patients with those of group 2 we found a significant difference after the use of the eye drops, with the OSI better in group 1 than in group 2 . This result is due to the normal increase in 
Table 5 Objective Scatter Index outcomes by age group

\begin{tabular}{lllllllll}
\hline Group & Right eye & \multicolumn{6}{l}{ Left eye } \\
\cline { 2 - 3 } & Before instillation & After instillation & $\boldsymbol{p}$ value & & Before instillation & After instillation & $\boldsymbol{p}$ value \\
\hline OSI Group 1 & $0.60 \pm 0.67$ & $0.44 \pm 0.29$ & 0.612 & & $0.52 \pm 0.39$ & $0.43 \pm 0.33$ & 0.404 \\
OSI Group 2 & $0.72 \pm 0.43$ & $0.71 \pm 0.56$ & 0.760 & & $0.64 \pm 0.42$ & $0.64 \pm 0.63$ & 0.726 \\
\hline
\end{tabular}

Values in table are presented as the mean \pm SD

OSI Objective Scatter Index
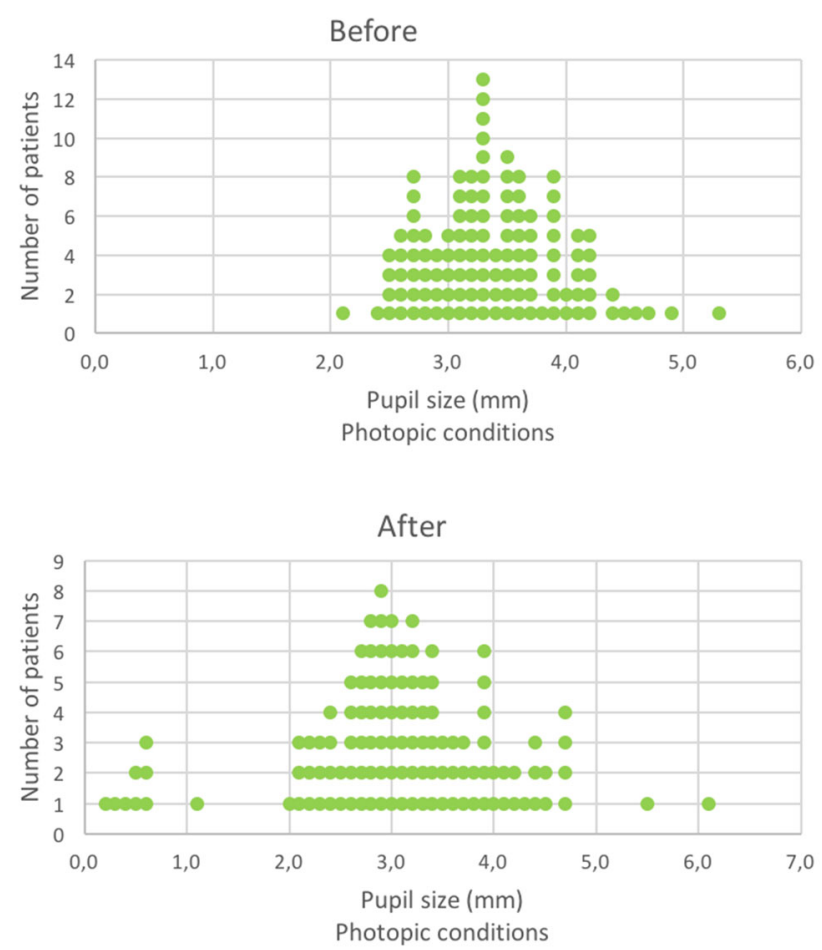

Fig. 4 Dot-plot of pupil diameter before and $2 \mathrm{~h}$ after the use of the eye drops under photopic light conditions. The change was significantly different at $p=0.001$

scattering secondary to the changes of the crystalline lens with aging and pupil miosis [6]. As an adverse effect, headaches were reported by 14 patients; these headaches are likely secondary to a ciliary spasm due to the use of pilocarpine. It was noted that the headaches diminished as the drug lost it effectiveness. Only one patient was intolerant to the eye drop preparation.

Although there was a significant change in pupil diameter, a dynamic pupil was maintained following use of the eye drop, which means that the pupil was still able to change its diameter under different light stimuli; this is referred to as "dynamic pseudoaccommodation." One of the limitations of our study was the lack of information on intraocular pressure, anterior chamber depth changes, and patient satisfaction, although we did reported on these parameters in our previous study [4]. A second limitation was that we did not assess subjective symptoms at night that might be experienced by the patients due to the small pupil diameter after the instillation of the eye drops. 

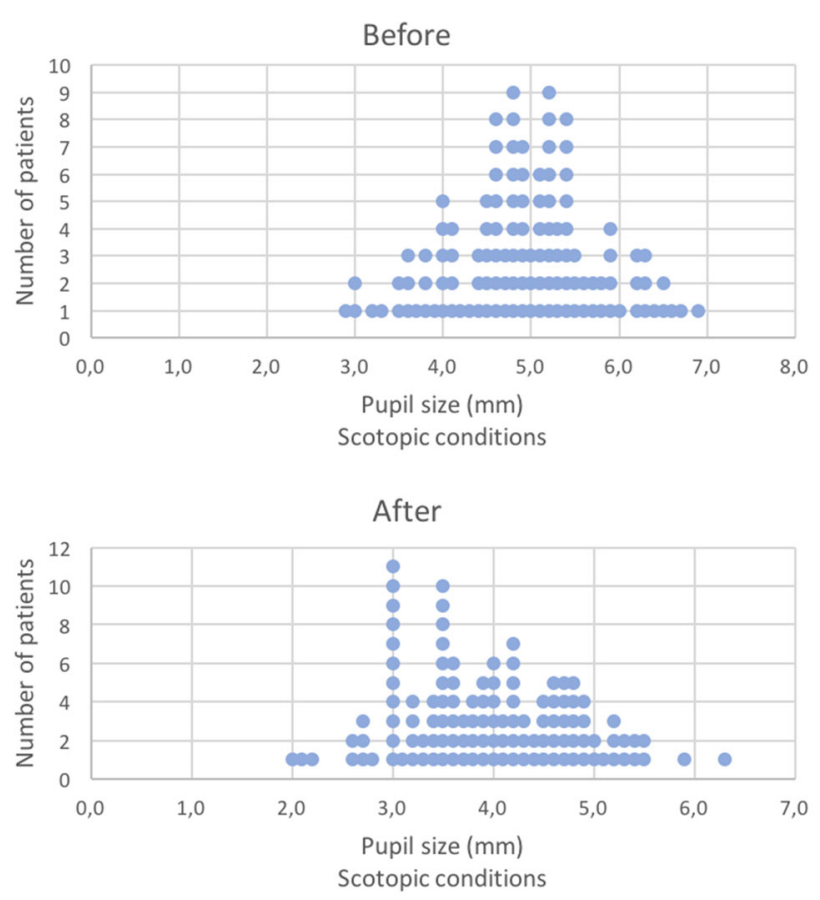

Fig. 5 Dot-plot of pupil diameter before and $2 \mathrm{~h}$ after the use of eye drops under scotopic light conditions. The change was significantly different at $p=0.000$ )

Table 6 Pupil diameter outcomes according to age group

\begin{tabular}{llllll}
\hline Light condition & \multicolumn{2}{l}{ Group 1 (41-50 years) } & & & \multicolumn{2}{l}{ Group 2 (51-65 years) } \\
\cline { 2 - 3 } \cline { 5 - 6 } & Before & After & & Before & After \\
\hline Photopic & $3.3 \pm 0.54$ & $3.1 \pm 0.78$ & & $3.5 \pm 0.65$ & $3.0 \pm 0.79$ \\
& $p=0.000$ & & $p=0.000$ & \\
Scotopic & $4.8 \pm 0.79$ & $4.0 \pm 0.81$ & & $4.8 \pm 0.90$ & $3.9 \pm 0.79$ \\
& $p=0.000$ & & $p=0.000$ & \\
\hline
\end{tabular}

Values in table are presented as the mean $\pm \mathrm{SD}$, in units of millimeters

The rationale for the combination of drugs selected for the FOV tears is as follows. Pilocarpine produces ciliary body contraction and stimulates accommodation, it also induces miosis, which increases the depth of focus. Naphazoline intensifies the relaxing effect of pilocarpine on the dilator pupillae. Nepafenac, pheniramine, and phenylephrine counteract ciliary muscle spasm, hyperemia, and excessive pupil constriction induced by pilocarpine. Polyethyleneglycol lubricates the eye and stops the burning sensation caused by all the others drugs, leveling the $\mathrm{pH}[4,8]$.

There are only a few published scientific reports on topical treatment for presbyopia [4, 8-10]. In most of these studies, a miotic was used to increase the depth of focus and improve near vision, and in some others, only one eye was treated [10]. Our treatment was binocularly instilled; as a result, no monovision was induced, creating a more physiological effect. 
All of the current presbyopia treatments have their side effects and complications. Monovision may result in loss of stereopsis [11, 12], and a good intraocular blur suppression is necessary [12]. Corneal inlays can also result in monovision and such complications as corneal haze, which requires explantation of the inlay, have been reported [13]. PresbyLASIK has the disadvantage of decreasing distance vision [3, 14], and a multifocal intraocular lens (IOL) cannot be implanted afterwards. Implantation of an IOL is an intraocular intervention that can produce halos and glare $[15,16]$, and there is the need for neuroadaptation [16]. It should be noted that there is a risk of infection in all of the procedures as they are invasive. With this new topical treatment, we do not have such side effects, although the gain of lines in near vision varies in each patient. The main advantage of FOV tears is that the effect is only temporary, so if any adverse effect does occur (e.g., headaches) they disappear as the drug losses its effectiveness.

\section{CONCLUSIONS}

The outcomes of this study indicate that $2 \mathrm{~h}$ after the instillation of the eye drop the therapy was effective in improving near vision in $92.3 \%$ of the patients, with a small number of patients showing intolerance to the use of this topical compound. This is a step forward toward a noninvasive treatment of presbyopia. Long-term follow-up studies are necessary to establish the long-term efficacy and tolerance of this type of presbyopic treatment and patient satisfaction following this new pharmacological approach for the treatment of presbiopia.

\section{ACKNOWLEDGEMENTS}

We express our deep appreciation to the participants of this study.

Funding. No funding or sponsorship was received for this study or publication of this article.
Authorship. All named authors meet the International Committee of Medical Journal Editors (ICMJE) criteria for authorship for this article, take responsibility for the integrity of the work as a whole, and have given their approval for this version to be published.

Disclosures. Felipe Vejarano $\mathrm{MD}$ is the owner of the patent of the eye drops FOV tears. Jorge L. Alio does not have a financial disclosure. Veronica Vargas does not have a financial disclosure.

Compliance with Ethics Guidelines. Each participant provided written informed consent, and all procedures performed in the study followed the 1964 Declaration of Helsinki of and its later amendments. It also received approval of the ethics committee of Fundación Oftalmológica Vejarano in Popayán, Colombia.

Data Availability. The datasets during and/ or analyzed during the current study are available from the corresponding author on reasonable request.

Open Access. This article is distributed under the terms of the Creative Commons Attribution-NonCommercial 4.0 International License (http://creativecommons.org/licenses/ by-nc/4.0/), which permits any noncommercial use, distribution, and reproduction in any medium, provided you give appropriate credit to the original author(s) and the source, provide a link to the Creative Commons license, and indicate if changes were made.

\section{REFERENCES}

1. Goertz AD, Stewart WC, Burns WR, Stewart JA, Nelson LA. Review of the impact of presbyopia on quality of life in the developing and developed word. Acta Ophthalmol. 2014;92:497-500.

2. Davidson RS, Dhaliwal D, Hamilton R, et al. Surgical correction or presbyopia. J Cataract Refract Surg. 2016;42:920-30.

3. Vargas-Fragoso V, Alió J. Corneal compensation of presbyopia: PresbyLASIK: an updated review. Eye Vis (Lond). 2017;4(11):1-8. 
4. Renna A, Vejarano LF, De la Cruz E, Alió JL. Pharmacological treatment of presbyopia by novel binocularly instilled eye drops: a pilot study. Ophthalmol Ther. 2016;5:63-73.

5. Cochener B, Patel S, Galliot F. Correlational analysis of objective and subjective measures of cataract quantification. J Refract Surg. 2016;32(2):104-9.

6. Alió JL, Schimchak P, Negri HP, Montés-Micó R. Crystalline lens optial dysfunction through aging. Ophthalmology. 2005;112:2022-9.

7. Artal P, Benito A, Pérez GM, et al. An Objective Scatter Index based on double-pass retinal images of a point source to classify cataracts. PLoS One. 2011;6(2):e16823. https://doi.org/10.1371/journal. pone.0016823.

8. Çalis Karanfil F, Turgut B. Update on presbyopiacorrecting drops. Eur Opthal Rev. 2017;11(2):1-5.

9. Benozzi J, Benozzi G, Orman B. Presbyopia: a new potential pharmacological treatment. Med Hypothesis Discov Innov Opthalmol J. 2012;1:3-5.

10. Abdelkader A. Improved presbyopic vision with miotics. Eye Contact Lens. 2015;41:323-7.
11. Hayashi K, Ogawa S, Manabe SI, Yoshimura K. Binocular visual function of modified pseudphakic monovision. Am J Ophthalmol. 2016;159(2):232-40.

12. Mahrous A, Ciralsky JB, Lai EC. Revisiting monovision for presbyopia. Curr Opin Ophthalmol. 2018;29:313-7.

13. Ong HS, Chan AS, Yau CW, Mehta JS. Corneal inlays for presbyopia explanted due to corneal haze. J Refract Surg. 2018;34(5):357-60.

14. Alió J, Amparo F, Ortiz D, Moreno L. Corneal multifocality with excimer laser for presbyopia correction. Curr Opin Ophthalmol. 2009;20:264-71.

15. Rosen E, Alió J, Dick H, Dell S, Slade S. Efficacy and safety of multifocal intraocular lenses following cataract and refractive lens exchange: metaanalysis of peer-reviewed publications. J Cataract Refract Surg. 2016;42(2):310-28.

16. Alio JL, Plaza-Puche AB, Fernandez-Buenaga R, Pikkel J, Maldonado M. Multifocal intraocular lenses: an overview. Surv Ophthalmol. 2017;62(5):611-34. 